\title{
Comparative Study of Kefir Yogurt-Drink and Sodium Fluoride Mouth Rinse on Salivary Mutans Streptococci
}

\author{
${ }^{1}$ Maryam Ghasempour, ${ }^{2}$ Seyyed Ali Asghar Sefidgar, ${ }^{3}$ Ali Akbar Moghadamnia, ${ }^{4}$ Reza Ghadimi \\ ${ }^{5}$ Samane Gharekhani, ${ }^{6}$ Leila Shirkhani
}

\begin{abstract}
Aim: The level of mutans streptococci (MS) is reduced by regularly consumption of probiotic Kefir drink. The present study aiming at answer to this question 'may the Kefir drink be considered an alternative to fluoride rinse?'
\end{abstract}

Materials and Methods: Twenty-two healthy volunteers aged 22-32 years with good oral hygiene participated in this study. None of participants had received any antibiotic or antimicrobial agent or professional fluoride therapy within the last month. None of them exhibited active caries lesions. Smokers and subjects who have chewing gums xylitol habit or who were undergoing orthodontic treatment were excluded. In a cross over design with 2 parallel groups, people in group A for 2 weeks received $100 \mathrm{ml}$ of Kefir drink per day, then avoided brushing, eating and drinking for an hour. Simultaneously, people in group $B$ were administered $0.05 \%$ sodium fluoride rinse in the same manner. After washout period, people in groups $A$ and $B$ respectively used $0.05 \%$ sodium fluoride rinse and Kefir drink. Saliva sampling was performed before and after interventions. The acidity and the count of MS were assessed and data were analyzed statistically.

Result: There was no significant difference between base line $\mathrm{pH}$ values of saliva in study groups $(\mathrm{p}>0.05)$. Although, a significant difference was shown between MS counts before and after interventions $(p \leq 0.0001$ and $p \leq 0.0001$ for $\mathrm{NaF}$ and Kefir respectively), but the equal inhibitory effect was found between study groups $(p>0.05)$.

Conclusion: Kefir drink can inhibit salivary MS as well the sodium fluoride rinse. This beverage may be considered an alternative for fluoride rinse.

Clinical significance: Probiotics containing dairy products was known with anticariogenic properties. These agents may be used in caries control strategies adjunctively.

\footnotetext{
${ }^{1,4,5}$ Assistant Professor, ${ }^{2}$ Associate Professor, ${ }^{3}$ Professor

${ }^{6}$ Non-faculty Investigator

${ }^{1,5}$ Department of Pediatric Dentistry, Babol University of Medical Sciences, Iran

${ }^{2,6}$ Department of Mycology, Babol University of Medical Sciences, Iran

${ }^{3}$ Department of Pharmacology, Babol University of Medical Sciences, Iran

${ }^{4}$ Department of Community Medicine, Babol University of Medical Sciences, Iran
}

Corresponding Author: Samane Gharekhani, Department of Pediatric Dentistry, Ganj Afrooz Street, Babol University of Medical Sciences, Iran, e-mail: sgharekhani@gmail.com
Keywords: Fluoride mouth rinse, Kefir, Mutans streptococci.

How to cite this article: Ghasempour M, Sefidgar SAA, Moghadamnia AA, Ghadimi R, Gharekhani S, Shirkhani L. Comparative Study of Kefir Yogurt-Drink and Sodium Fluoride Mouth Rinse on Salivary Mutans Streptococci. J Contemp Dent Pract 2014;15(2):214-217.

Source of support: Student Research Committee of Babol University of Medical Sciences.

\section{Conflict of interest: None}

\section{INTRODUCTION}

Oral cavity has been known as a complex nest for many of microorganisms are competing with each other to obtain food, shelter and growth opportunities. By understanding the interactions between them, pathogenic strains can be inhibited or selectively removed indirectly. ${ }^{1}$ In term, this approach is named 'Bacteriotherapy' aiming at control decay by reducing or inhibiting cariogenic bacteria. ${ }^{2}$

The most important caries causing bacteria are mutans streptococci (MS) species. This group includes Streptococcus mutans and Streptococcus sobrinus that are responsible for occlusal and smooth dental surfaces caries respectively. ${ }^{3}$

Historically fluoride has been considered as a major cariostatic element that primarily affects smooth surfaces caries. ${ }^{3}$ It is applied in various forms and doses. One of the most common applications of fluoride is mouth rinse. It is found that a long-term use of daily fluoride rinse can reduce level of salivary MS species in addition to remineralization of initial caries lesions. ${ }^{4-6}$ Besides professional dental services, fluoride mouth rinse is suggested for high-risk dental patients, such as orthodontic patients, pregnant or new mothers and adolescents who suffering rampant caries. ${ }^{7-9}$

It is interested that increasing the application of fluoridated dental care products, resulted in a decreasing rate of decay in children, while dental caries in adolescents especially on occlusal surfaces has remained high. ${ }^{10}$

It seems that when the parental supervision on their teenager's oral hygiene is removed, bad dietary habits such as frequently intake of snacks and some soft drinks as well as reluctance or neglect in dental self-care or application of the fluorinated products by the juveniles are some of main factors contributing in high incidence of dental caries in this group. ${ }^{3}$ 
Unfortunately, in spite of good attempts were made to preserve oral hygiene, dietary pattern, is less considered by patients or even dentists. It is necessary to advise patients about good dietary habits to prevent caries. One of the excellent food sources in this field is probiotic fermented dairy products. Application of the Probiotic products or in term, bacteriotherapy is an alternative approach to regulate the ecology of oral cavity by reducing the number of cariogenic bacteria. The word 'probiotic' against 'antibiotic' has been introduced to inhibit, reduce or selectively removal of the pathogenic bacteria as well as to prevent the emergence of resistant strains. ${ }^{11}$

One of the probiotic dairy sources, the probiotic drink Kefir, is popular in Middle East. This drink is produced by fermentation of the Kefir grains containing probiotic lactobacilli and yeasts. This beverage is full of vitamin $\mathrm{K}$, $\mathrm{B}_{1}, \mathrm{~B}_{2}$, calcium, folic acid and amino acids that is used to promote general health and to control of many diseases. ${ }^{12}$

The authors think that, beside the good taste and availability, this fact that people don't look to drink as a drug, is the advantage of this product.

Previously, a randomized, controlled study has demonstrated the inhibitory effect of Kefir drink on MS species. ${ }^{13}$ Under the assumption that adding Kefir drink to diet as well the sodium fluoride mouth rinse can reduce the number of MS species in saliva, this study is planned to compare the inhibitory effect between probiotic drink Kefir and sodium fluoride $(\mathrm{NaF})$ mouth rinse on salivary mutans streptococci species.

\section{MATERIALS AND METHODS}

\section{Subjects}

A total of 22 healthy volunteers (11 males and 11 females) aged 22-32 years participated in this study. The informed consent was obtained from each subject. Also, the study protocol was approved by the ethics committee of the Babol University of Medical Sciences, Babol, Iran and it was registered in the Iranian Registry of Clinical Trials (IRCT) system with registration number IRCT201204119271N2. All participants had good oral hygiene and had not received any antibiotic or antimicrobial agent or professional fluoride therapy within the last month. None of them exhibited active or untreated caries lesions. Smokers and subjects whit chewing gums xylitol habit or who were undergoing orthodontic treatment were excluded from present study.

\section{Study Design}

This study was designed as a cross over randomized, controlled trial with two parallel groups. Following the 'run-in' period lasted 7 days that the participants were instructed not to use any probiotics products, people in group A for
2 weeks swished and drank $100 \mathrm{ml}$ of Kefir drink per day, then avoided brushing, eating and drinking for an hour $(n=11)$. Simultaneously, people in group B swished their mouth in the same method by $0.05 \% \mathrm{NaF}$ mouth rinse $(\mathrm{n}=11)$. After 4 weeks (wash-out) period, people in groups A and B respectively used $0.05 \% \mathrm{NaF}$ mouth rinse and Kefir drink in the cited manner. Totally, all 22 participants received both Kefir drink and NaF mouth rinse. Also, all of them were brushing their teeth with fluoride-containing toothpastes during the study while the use of other fluoridated products was avoided.

\section{Kefir Yogurt-Drink Preparation}

The homemade Kefir drink was used in this study. After boiling milk (1.5\% fat, Pegah Dairy Co, Iran) and cooling it at room temperature, $5 \%$ of Iranian Kefir grains (containing Lactobacillus casei subsp. Pseudo plantarum and Saccharomyces cerevisiae and $\mathrm{pH}=4$ ) were added. The fermentation was done at $25^{\circ} \mathrm{C}$ for 48 hours, and then the Kefir grains were separated by filtering. ${ }^{12}$

\section{Clinical Examination, Saliva Sampling}

A dentist examined the subject's oral health using World Health Organization (WHO) criteria to rule out the presence of untreated active caries lesion. Unstimulated saliva sample was collected from each person before and after every intervention to measure its $\mathrm{pH}$ by $\mathrm{pH}$ indicator paper (ARAK Chemical Co, Iran) and count of MS. To minimize circadian rhythm effects, saliva sampling was done in the morning. The subjects were ordered not to eat or drink for an hour before the saliva sampling.

\section{Laboratory Tests}

The counts of mutans streptococci species were evaluated by culturing method. One loop of $10^{-3}$ dilution of saliva inoculated on blood agar plate (Merk, Germany) at $37^{\circ} \mathrm{C}$ for 48 hours. For different cultured colonies in size and shape, several biochemical tests, such as Gram staining, Catalase test, Resistance to Optochin (Sigma-Aldrich, USA) and Bacitracin discs (Padtan teb, Iran), Hydrolysis of Esculin (Himedia, India) and fermentation of the manitol and sorbitol (Sigma-Aldrich, USA) were done. Based on Bergy's manual, the colonies similar to isolated MS were counted. ${ }^{14}$

\section{Statistical Analysis}

Student t-test was used to compare the MS counts between two groups. The test was also used to evaluate changes in $\mathrm{pH}$ values of saliva before and after interventions. The differences between data of groups were considered statistically significant at $\mathrm{p}$-value under 0.05 . 
Table 1: Mean values of mutans streptococci species CFU/ml of saliva, before and after interventions

\begin{tabular}{|c|c|c|c|c|c|}
\hline Groups & & $\begin{array}{l}\text { Pre-intervention } \\
\left(10^{5} \mathrm{CFU} / \mathrm{ml} \text { of saliva) }\right.\end{array}$ & $\begin{array}{l}\text { Post-intervention } \\
\left(10^{5} \mathrm{CFU} / \mathrm{ml} \text { of saliva) }\right.\end{array}$ & $\begin{array}{l}\text { Delta } \\
\left(10^{5} \mathrm{CFU} / \mathrm{ml} \text { of saliva) }\right.\end{array}$ & $p$-value \\
\hline \multirow[t]{2}{*}{$\mathrm{NaF}$ mouth rinse } & Mean & 5.375 & 2.632 & *2.743 & $\leq 0.0001$ \\
\hline & SD & 1.687 & 1.203 & 1.370 & \\
\hline \multirow[t]{2}{*}{ Kefir drink } & Mean & 5.282 & 2.975 & *2.261 & $\leq 0.0001$ \\
\hline & SD & 1.644 & 1.264 & 1.588 & \\
\hline
\end{tabular}

*Non-significant difference between two groups $(p>0.05)$

\section{Result}

There was no significant difference between $\mathrm{pH}$ values of saliva before and after interventions ( $\mathrm{p}>0.05$ ) (Fig. 1).

Although, a significant difference was shown between salivary MS counts before and after interventions ( $\mathrm{p} \leq 0.0001$ and $\mathrm{p} \leq 0.0001$ for $\mathrm{NaF}$ and Kefir; respectively), but the equal inhibitory effect was found between study groups $(\mathrm{p}>0.05)$ (Table 1$)$.

\section{DISCUSSION}

In the present study, Kefir yogurt-drink containing probiotic Lactobacillus casei subsp. Pseudo plantarum and Saccharomyces cerevisiae could reduce salivary MS species count as well sodium fluoride mouth rinse. Unfortunately, less data exist on the efficacy of Kefir in caries prevention and such a comparison had not been done previously. The only in vivo study about the effect of Kefir drink on cariogenic bacteria count was carried out by Cugulo et al. They showed that 3 weeks consumption of Kefir yogurtdrink, 2 times per day could be effective on reduction of MS count. ${ }^{13}$ As previously mentioned, some of milk based products, such as yogurt and yogurt-drink contain probiotic microorganisms that are found a main factor in caries prevention. ${ }^{13,15}$ Probiotics can inhibit their pathogenic neighborhoods by interfering with biofilm formation, cellular adhesion and colonization. ${ }^{15-18}$

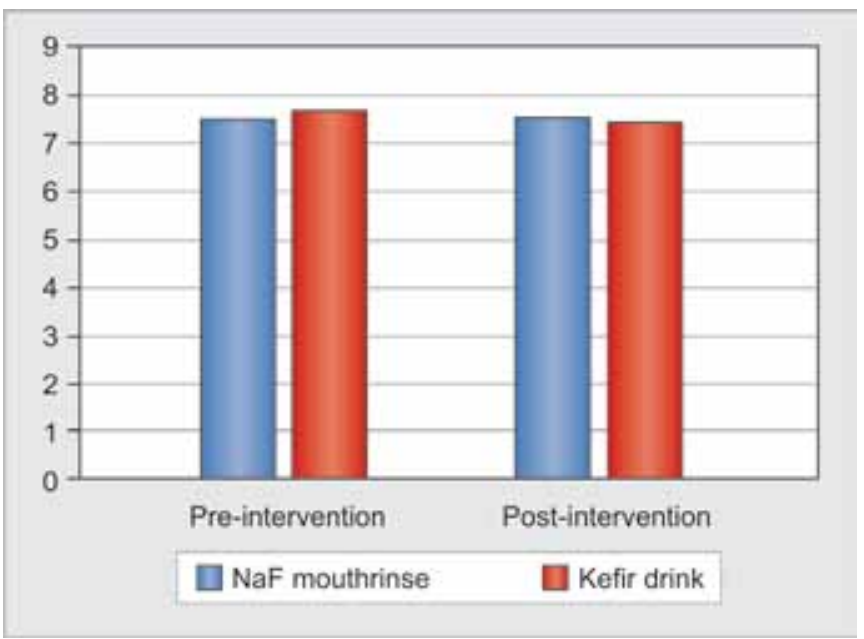

Fig. 1: Mean values of $\mathrm{pH}$ of saliva before and after interventions
Interestingly, the remineralization potential was also reported for probiotic milk-based products. ${ }^{19,20}$ It seems that the presence of calcium and other constituents which may protect enamel against dental pathogen is responsible for remineralization process. ${ }^{21}$ Thereafter, in view of authors, probiotic products may be considered an alternative for fluoride mouth rinse especially in young children who not be allowed to use fluoride mouth rinse.

Considering the low $\mathrm{pH}$ of Kefir yogurt-drink, there was a concern if it may drop $\mathrm{pH}$ of saliva under critical value. In this study after 2 weeks daily consumption of Kefir yogurt, no significant change was found in $\mathrm{pH}$ of saliva. Indeed, the buffering capacity of milk and saliva may regulate the $\mathrm{pH}^{21}$

Since lactobacilli are responsible for caries development in deep lesions, ${ }^{22-24}$ there is another concern if probiotic lactobacilli may increase other salivary lactobacilli count. Cugulo et al were demonstrated reduction of lactobacilli as well as mutans streptococci species in saliva with intake of Kefir drink for 3 weeks. ${ }^{13}$ Unlikely, Montalto et al were reported an increased salivary lactobacilli count with probiotics application. ${ }^{25}$ However, this issue has been not clearly demonstrated so care must be taken to prescribe the probiotic products for patients who are suffering untreated dental caries. ${ }^{26}$

\section{CONCLUSION}

Kefir drink and sodium fluoride mouth rinse were equally effective in reducing the count of salivary mutans stereptococci. Beside of good oral hygiene, consumption of Kefir drink is especially suggested for teenagers. Further studies with larger sample size and preferably, both on low- and high-risk population should be done to confirm the present results.

\section{CLINICAL SIGNIFICANCE}

Probiotics containing dairy products was known with anticariogenic properties. These agents may be used in caries control strategies adjunctively.

\section{REFERENCES}

1. He X, Lux R, Kuramitsu HK, Anderson MH, Shi W. Achieving Probiotic Effects via Modulating Oral Microbial Ecology. Adv Dent Res 2009;21(1):53-56. 
2. Caglar E, Kavaloglu SC, Kusku OO, Sandalli N, Holgerson PL, Twetman S. Effect of chewing gums containing xylitol or probiotic bacteria on salivary mutans streptococci and lactobacilli. Clin Oral Invest 2007;11:425-429.

3. Dean JA, Avery DR, McDonald RE. Dentistry for the child and adolescents. 9th ed. MOSBY 2011. p. 206.

4. Kaneko N, Yoshihara A, Ida H, Nomura Y, Imai S, Nisizawa T, Sakuma S, Hanada N, Miyazaki H. Influence of a fluoride mouthrinse on mutans streptococci in schoolchildren. Caries Res 2006;40(6);501-507.

5. Yoshihara A, Sakuma S, Kobayashi S, Miyazaki H. Antimicrobial effect of fluoride mouthrinse on mutans streptococci and lactobacilli in saliva. Pediatr Dent 2001;23(2):113-117.

6. Sundas S, Rao A. Comprative evaluation of chlorhexidine and sodium fluoride mouthwashes on streptococcus mutans. J Nepal Dent Assoc 2011;12(1):17-21.

7. O'Reilly MM, Featherstone JDB. Demineralization and remineralization around orthodontic appliances: An in vivo study. American J Ortho Dent facial Orthoped 1987;92(1):33-40.

8. Adair SM. The role of fluoride mouthrinses in the control of dental caries: a brief review. Pediatric Dent 1998;20(2):101-104.

9. Gomez SS, Weber AA. Effectiveness of a caries preventive program in pregnant women and new mothers on their offspring. Inter J Paed Dent 2001;11(2):117-122.

10. Simark-Mattsson C, Emilson CG, Grahn Hakansson E, Jacobsson C, Holm S. Lactobacillus-mediated interference of mutans streptococci in caries-free vs. caries-active subjects. Eur J Oral Sci 2007;115:308-314.

11. Agarwal E, Bajaj P, Guruprasad CN, Naik S, Pradeep AR. Probiotics: a novel step towards oral health. AOSR 2011; 1(2):108-115.

12. Otles S, Cagondi O. Kefir: a probiotic dairy-consumption, nutritional and therapeutic aspects. Pakistan J Nutr 2003;2(2):54-59.

13. Cogulu D, Topaloglu A, Caglar E, Sandalli N, Karagozlu C, Ersin N, Yerlikaya O. Potential effects of a multistrain probiotic-Kefir on Streptococcus mutans and Lactobacillus spp. J Dent Sci 2010; 5(3):144-149.
14. Noel RK, Holt JG. Bergey's manual of systematic bacteriology. Williams and Wilkins 1998;1-10.

15. Twetman S, Stecksen-Blicks C. Probiotics and oral health effects in children. Int J Ped Dent 2008;18:3-10.

16. Bonifait L, Chandad F, Grenier D. Probiotics for oral health: myth or reality? JCDA 2009;75(8):585-587.

17. Tahmourespour A, Kermanshahi RK. The effect of a probiotic strain (Lactobacillus acidophilus) on the plaque formation of oral Streptococci. Bosn J Basic Med Sci 2011;11(1):37-40.

18. Tahmourespour A, Salehi R, Kermanshahi RK, Eslami G. The anti-biofouling effect of Lactobacillus fermentum-derived biosurfactant against Streptococcus mutans. Biofouling 2011; 27(4):385-392.

19. Koretz RL. Probiotics, critical illness and methodological bias. Nutr Clinic Pract 2009;24:45-49.

20. Petersson LG, Magnusson K, Hakestam U, Baigi A, Twetman S. Reversal of primary root caries lesions after daily intake of milk supplemented with fluoride and probiotic lactobacilli in older adults. Act Odont Scand 2011;69(6):321-327.

21. Saraf K, Shashikanth MC, Priya T, Sultana N, Chaitanya N. Probiotics-Do they have a Role in Medicine and Dentistry? JAPI 2010;58:488-492.

22. Ayna B, Celenk S, Atakul F, Sezgin B, Ozekinci T. Evaluation of clinical and microbiological features of deep carious lesions in primary molars. J Dent Child 2003;70(1):15-18.

23. Badet C, Thebaud NB. Ecology of Lactobacilli in the Oral Cavity: A Review of Literature. Open Microbiol J 2008;2:38-48.

24. Tanzer JM, Livingston J, Thompson AM. Microbiology of primary dental caries in humans. J Dent Educ 2001;65(10):1028-1037.

25. Montalto M, Vastola M, Marigo L, Covino M, Graziosetto R, Curigliano V, Santoro L, Cuoco L, Manna R, Gasbarrini G. Probiotic treatment increases salivary counts of lactobacilli: a double-blind, randomized controlled study. Digestion 2004;69: 53-56.

26. Haukioja A, Söderling E, Tenovuo J. Acid production from sugars and sugar alcohols by probiotic lactobacilli and bifidobacteria in vitro. Caries Res 2008;42(6):449-453. 